\title{
NÃO HÁ LUGAR MELHOR QUE NOSSO LAR - A CASA COMO CONFINAMENTO, PERSONAGEM E ESPAÇO IDEALIZADO NO FILME ORGULHO E PRECONCEITO
}

\author{
Karina Gomes Barbosa \\ Universidade Católica de Brasília
}

\begin{abstract}
Resumo: O presente artigo procura analisar três maneiras pelas quais a figura da casa é representada na versão cinematográfica de 2005 da obra literária Orgulho e Preconceito: como espaço de confinamento, como personagem e como espaço idealizado de afeto. Para servir de amparo à análise dessa adaptação de um dos livros de Jane Austen, utilizamos as teorias do cinema e da cultura de massa e as teorias feministas. Pousar o olhar sobre a linguagem cinematográfica da obra audiovisual nos permite mostrar como, longe de ser um espaço idealizado e pacificado como o filme tenta fazer transparecer, a figura da casa tem escamoteados todos os outros sentidos e significados que possui na narrativa e, especialmente, na história de vida da das personagens femininas, para oferecer um reforço ficcional à visão patriarcal da casa como único espaço permitido à heroína, que tem permissão para transitar em espaços muito distintos daqueles percorridos pelo herói masculino.
\end{abstract}

Palavras-chave: Cinema. Casa. Amor. Adaptação. Happy end

\section{Considerações iniciais}

Inglaterra, 1817. Na manhã do dia 18 de julho, Jane Austen morre ${ }^{1}$, aos 41 anos, na casa em que vivia com a mãe e a irmã, em Chawton. Fim de dezembro, 1817. Henry Thomas, um dos irmãos de Jane, publica os dois últimos romances completados pela autora (de um

\footnotetext{
(c) (1)

EY No ND Esta obra está licenciada sob uma Licença Creative Commons.
}

\footnotetext{
* Doutoranda em Comunicação Social pela Universidade de Brasília na linha Imagem e Som. Mestre em Comunicação Social, na linha Imagem e Som, pela Universidade de Brasília (2009). Graduada em Comunicação Social pela Universidade de Brasília (2006) e em Relações Internacionais pela Universidade de Brasília (2002). Foi bolsista da Universidade de Brasília. Professora da Universidade Católica de Brasília, onde coordena o laboratório digital, o jornal-laboratório, a revista de jornalismo e a implantação do portal-laboratório de convergência digital do curso. Como jornalista, tem passagens pelo CorreioWeb, Editora Abril, PSDB, Hoje em Dia e Ministério de Minas e Energia.

${ }^{1}$ Do que, hoje, a ciência afirma ter sido mal de Addison ou linfoma, a partir dos registros médicos da escritora. Uma nova possibilidade, mais recente, é que ela teria sido vítima de envenenamento acidental por arsênico.
} 
total de seis), Persuasão e A Abadia de Northanger, em volume conjunto. O primeiro havia sido terminado em 6 de agosto do ano anterior; o segundo foi o terceiro livro escrito por Austen (finalizado em 1799) e oferecido para publicação (e rejeitado), sob o nome de Susan, em abril de 1803. Foram 1.750 cópias em papel barato que Austen nunca chegou a ver, das quais 1.409 foram vendidas em um ano, segundo Jan Ferguss, que escavou os dados relativos à publicação de cada livro, bem como o engajamento da inglesa na publicação de cada um deles, a partir de cartas e registros históricos (2008).

Apesar de ter sido rejeitada pelos editores duas vezes (antes de Susan, o manuscrito de First Impressions - depois Orgulho e Preconceito - já havia sido devolvido em 1797), Jane Austen estava determinada a publicar $^{2}$. Quando, enfim, conseguiu ver seu primeiro livro impresso, já corria o ano de 1811. O volume era Razão e Sensibilidade (antes chamado Elinor \& Marianne) e a primeira edição vendeu 750 cópias. A segunda publicação, Orgulho e Preconceito, saiu em janeiro de 1813 e foi o livro mais popular da autora. Chegou a ser o romance da moda, à época, e a primeira edição teve em torno de 1000 exemplares. Uma segunda edição saiu no mesmo ano, com mais 750. Mansfield Park foi publicado em 1814, possivelmente com 1.250 cópias - consideradas poucas. A edição esgotou em apenas seis meses, menos que os oito meses ou o ano e meio do segundo e primeiro livros, respectivamente.

No final de 1815 sai Emma e, logo em seguida, a segunda edição de Mansfield Park. Emma teve 2 mil exemplares - em quatro anos, a primeira edição não chegou a se esgotar (1.437 cópias vendidas). Já a segunda edição de Mansfield Park naufragou: segundo o site The John Murray Archive, que reúne os arquivos do editor original do romance, foram 36 exemplares apenas ${ }^{3}$. A soma é simples, a partir dos levantamentos de Ferguss: em vida, Austen vendeu em torno de cinco mil exemplares de quatro livros, tiragem hoje maior que a inicial para um livro no Brasil (3 mil exemplares, em média) e muito inferior à tiragem contemporânea de um romance nos EUA ou na Inglaterra. Apesar de esgotar algumas edições e ser "moda", Austen não foi a autora mais popular de sua geração, um momento "quando oportunidades para mulheres publicarem nunca haviam sido maiores"4 (FERGUSS, 2008, p. 13).

\footnotetext{
2 Jan Ferguss conta que Austen vendeu os direitos de Susan em 1803, mas o livro nunca foi publicado. Em 1809, ela enviou uma carta irada aos editores questionando a demora. Na assinatura, Mrs. Ashton Dennis era o pseudônimo. As iniciais formavam o acrônimo M.A.D. (brava, em inglês) e, segundo Ferguss, "a carta deixa clara sua determinação para publicar" (2008: 19).

${ }^{3}$ The John Murray Archive, http://digital.nls.uk. Acesso em 22/02/2012.

${ }^{4}$ Tradução livre da autora.
} 
Uma cidade qualquer do hemisfério ocidental, século XXI. Livrarias dedicam estandes exclusivos às inúmeras edições de cada um dos livros de Jane Austen - e aos trabalhos anteriores, Juvenilia (que inclui o manuscrito de The Watsons), assim como ao inacabado Sandition. Versões bilíngues, obras completas, edições de bolso. Livrarias on-line têm seções com mais de três mil volumes das obras - em capa dura, edição simples, livros eletrônicos e audiobooks. Mais que isso: escritores usam as obras da inglesa como fontes para mash-ups ${ }^{5}$ nos quais os personagens do interior inglês dos séculos XVIII e XIX convivem com zumbis, monstros marinhos ou são homossexuais.

Logo após sua morte, a família de Austen (mais notadamente o irmão-publicista, Henry Thomas, alegadamente o preferido dela) tentou construir a imagem de uma mulher que escrevia por não poder fugir ao chamado das letras, de acordo com Ferguss. A persona fica exposta na nota biográfica escrita por ele no volume duplo que contém A Abadia de Northanger e Persuasão e incluiu um processo de destruição de grande parte da correspondência da autora.

Mas Jan Ferguss demonstra que, ao contrário, ela era uma escritora profissional, consciente do valor de suas obras e interessada em lucrar com a publicação. Ainda que tenha tomado decisões não tão acertadas (comprovadas pelo intrincado sistema de venda dos direitos de publicação da época), Austen era implacável no trato com seus editores e negociava preços, direitos autorais, qualidade do papel, prazos de publicação - longe, portanto, da imagem de uma dama que apenas desejava verter o talento no papel. Especula-se que Sandition, o romance que Austen começou a escrever em 1816, já com os primeiros sinais de debilidade física, tenha sido motivado, em parte, pelo desejo da escritora de gerar mais renda para as três mulheres solteiras da família, depois de uma débâcle financeira sofrida pelos irmãos, responsáveis por garantir a maior parte da renda anual da mãe e das duas irmãs.

O nome da autora, que permaneceu escondido pela assinatura de J. Austen nos romances, já era conhecido quando o príncipe regente "sugeriu" que Emma fosse dedicado a ele. Conhecido, porém, em círculos ínfimos da restrita sociedade leitora do período. Hoje, Jane Austen é um dos nomes mais clássicos da literatura inglesa, e também mais populares. $\mathrm{O}$

\footnotetext{
${ }^{5}$ Segundo o site Mashup, "arte recombinada, arte derivada (...) elementos de diferentes fontes são misturados (ou justapostos) para criar uma nova composição". Tradução livre da autora. http://www.mashmashup.com/. Acesso em: 22 fev. 2012.
} 
Index Translationum ${ }^{6}$, da Unesco, lista 894 traduções entre 1979 e 2011 (período de indexação do projeto); para o português, são 28 traduções. É também considerada uma das maiores inovadoras do realismo literário.

Ainda que ansiasse sucesso e reconhecimento (bem como o lucro), Jane Austen jamais poderia imaginar a ressonância cultural e transmidiática de suas histórias. A primeira edição de Emma, hoje, é vendida por mais de US\$ $200 \mathrm{mil}^{7}$. O manuscrito de The Watsons (cerca de 68 páginas - 12 restantes se encontram na biblioteca Pierpont Morgan, em Nova York, e outras se perderam da biblioteca Queen Mary, na Universidade de Londres, há alguns anos) foi leiloado em julho de 2011 por cerca de R\$ 1,6 milhão (993 mil libras). Comprado pela biblioteca Bodleian, de Oxford, é o mais antigo existente (provavelmente de 1804) e, incompleto, conta a história das filhas de um clérigo doente, que morre e deixa as mulheres na pobreza (o pai de Jane morreu no ano seguinte, 1805, o que pode ter contribuído para a nãopublicação) ${ }^{8}$.

E não é apenas no papel e nas formas de narrativa contemporâneas que os livros adquirem que a autora é revivida pelo público. Dispositivos representacionais audiovisuais, notadamente cinema e TV, são grandes espaços de adaptações da obra da autora. O site Imdb.com, maior agregador de conteúdo sobre cinema e televisão do mundo, lista 47 adaptações de obras da autora já realizadas para televisão ou cinema e dois novos filmes em desenvolvimento (até 2011). As abordagens são as mais diversas possíveis. Além de minisséries televisivas e filmes adaptados mais fidedignamente, versões contemporâneas das obras e até uma abordagem documental de um de seus livros, passando por três produções de Bollywood - alguns, variações modernas das histórias da autora, não chegam a constar na lista. A mais recente versão hollywoodiana de Orgulho e Preconceito foi indicada a quatro Oscar e arrecadou US\$ 121 milhões de bilheteria em todo o mundo e outros US\$ 53 milhões em vendas de DVD nos EUA, segundo o site The-Numbers ${ }^{9}$. Desde 1995, quando foram lançadas a minissérie da BBC de Orgulho e Preconceito; a versão de Ang Lee para Razão e Sensibilidade e uma versão atualizada de Emma, As Patricinhas de Beverly Hills ${ }^{10}$, uma série de filmes e conteúdos televisivos tem sido feita baseada na autora. Foram 20, até 2011.

\footnotetext{
${ }^{6} \mathrm{http} / /$ www.unesco.org/xtrans/bsstatlist.aspx?lg=0. Acesso em: 08 mar. 2012.

${ }^{7}$ Pelo site de comercialização de livros raros AbeBooks. http://www.abebooks.com. Acesso em: 22 mar. 2012. 8 Informações baseadas em reportagem do jornal The Guardian: http://www.guardian.co.uk/books/2011/jul/14/jane-austen-manuscript-the-watsons. Acesso em 16/03/2012. ${ }^{9}$ www.the-numbers.com. Acesso em: 13 mar. 2012.

${ }^{10} \mathrm{O}$ ano de 1995 foi mesmo especial para a presentificação de Austen no audiovisual: a autora foi listada como uma das entertainers daquele ano pela revista norte-americana Entertainment Weekly. "Including Austen in a
} 
Esse conjunto de produtos culturais literários, cinematográficos e televisivos, seja adaptações, atualizações e ressignificações, comprova a importância contemporânea de uma escritora inglesa que viveu na virada do século XVIII para o século XIX; nunca se casou; era ávida leitora, assim como sua família; e escreveu seis romances de amor: Razão $e$ Sensibilidade (Sense and Sensibility), Orgulho e Preconceito (Pride and Prejudice), Mansfield Park (Idem), Emma (Idem), Persuasão (Persuasion) e A Abadia de Northanger (Northanger Abbey).

Nesses filmes e minisséries, corporificamos, por meio de estratégias de representação que se adéquam a novos dispositivos representacionais, as heroínas de Austen em carne e osso. Em cada um desses produtos, o audiovisual amplifica, por meio da linguagem, a trajetória dessas heroínas, ao mesmo tempo em que silencia, apaga ou diminui outras características da obra da autora - notadamente, a ironia como figura de discurso é minimizada nas adaptações.

Os livros de Austen se passam em cenários circunscritos ao interior inglês e incluem acurados panoramas da sociedade de sua época, entre as décadas de 1790 e 1810 . Refletem as assimetrias de relações entre nobres, ricos e pobres; entre cavalheiros, damas, arrivistas e vigaristas; contêm ácidos comentários sociais. Mas são obras, sobretudo, de amor. Essa classificação pode querer dizer muita coisa ou nada. Quando nos voltamos para as narrativas literárias ou audiovisuais, especialmente as hollywoodianas ${ }^{11}$, derivadas destas obras, alguns questionamentos emergem. Um deles diz respeito às maneiras pelas quais o meio - e a linguagem - se apropria de certos elementos presentes na narrativa da autora inglesa para transmitir significados. Neste artigo, voltamos nosso olhar para a versão de Orgulho $e$ Preconceito de 2005 (Pride and Prejudice, Joe Wright) para tentar compreender como a ideia de casa representada no filme se articula com a noção de herói na cultura de massa e como exclui, como representação visual, uma série de sentidos relativos ao papel da mulher naquele espaço.

\section{Heróis e heroínas}

John McClane é um policial durão de Nova York. No Natal, vai para Los Angeles visitar a ex-mulher e os filhos. Ao chegar ao trabalho da esposa, para a confraternização de

trade listing of this kind reflects the fact that nearly every production was marketed and received as being primarily authored by the novelist", aponta Laura Carroll (2003).

${ }^{11}$ Entendemos Hollywood muito mais como um sistema de produção e codificação estética do audiovisual que somente um lócus. Por isso, filmes não produzidos nos estúdios norte-americanos podem ser considerados como do modelo hollywoodiano. 
fim de ano do emprego dela, se depara com uma ação terrorista que fez todos reféns. Com apenas um revólver, McClane consegue, sozinho, matar os terroristas um a um. Uma das sequências finais do filme apresenta o herói na casa da ex-mulher, com quem se reconcilia: o policial segura, aliviado, um porta-retratos dele com a família. Duro de Matar, 1988 (Die Hard, John McTiernan).

McClane (Bruce Willis) é um típico herói simpático à maneira descrita por Edgar Morin: "é o herói ligado identificativamente ao espectador. Ele pode ser admirado, lastimado, mas deve sempre ser amado. É amado, porque é amável e amante" (MORIN, 2011, p. 84). Portanto, falho, humano. Hiper-humano. É alguém com quem o espectador se identifica, ao mesmo tempo em que se projeta nele - o binômio projetividade-identificação apontado por Morin. A trajetória de McClane corresponde à do herói da cultura de massa que Morin descreve: após expiar as faltas do outro, o pecado original, torna-se invulnerável à morte e ganha o direito ao happy ending: "o herói que supera os riscos parece ter-se tornado invulnerável à morte" (MORIN, 2011, p. 85).

A trajetória empreendida pelo herói do filme de ação é semelhante, mas não igual, à milenar tradição narrativa que se desenvolveu, sobretudo, na tragédia clássica (e que permaneceu no teatro elisabetano, no romance, no melodrama e no primeiro cinema, diz Morin): o herói sai de casa, realiza uma missão com forte impacto social; "fixa sobre si, às vezes até a morte, a infelicidade e o sofrimento. Ele expia as faltas do outro, o pecado original de sua família, e apazigua, com seu sacrifício, a maldição ou a cólera do destino" (MORIN, 2011, p. 85).

Com a emergência da cultura de massa no cenário histórico ocidental, ao contrário da tragédia, o herói não mais atenua, com seu sofrimento, a maldição ou a cólera do destino. Ao contrário: invulnerável à morte, recebe como recompensa o final feliz. Diz Morin: "o happy end não é reparação ou apaziguamento, mas irrupção da felicidade" (MORIN, 2011, p. 85). É conquista. Podemos sumarizar assim: a jornada do herói na cultura de massa é um sair de casa, enfrentar o mundo e voltar à casa para um novo status quo, mais feliz. Ou, como afirma Todorov, "a passagem de um equilíbrio a outro" (TODOROV, 2006, p. 138). Bordwell chama de história canônica a este "padrão canônico de estabelecimento de um estado inicial de coisas que é violado e deve ser restabelecido" (BORDWELL, 2005, p. 279). Este novo equilíbrio, contudo, integra um imaginário em que a felicidade é o núcleo afetivo, de acordo com Morin. 
Tal happy ending corresponde, assim, à reconquista da família e do amor. McClane, personagem de Duro de Matar, não está sozinho. De acordo com David Bordwell, "geralmente o syuzhet clássico apresenta uma estrutura causal dupla, duas linhas de enredo: uma que envolve o romance heterossexual (rapaz/moça, marido/mulher), e outra que envolve uma outra esfera" (BORDWELL, 2005, p. 280). A outra esfera pode ser o trabalho, a guerra, uma missão. O que permanece é a constância do amor como estrutura causal e que leva, na conclusão narrativa, ao final feliz. "É significativo que, de cem filmes hollywoodianos escolhidos aleatoriamente, mais de sessenta finalizem com uma exibição do casal romântico o clichê de "final feliz"' (BORDWELL, 2005, p. 283). A jornada do herói da cultura de massa, portanto, está intimamente conectada à conquista amorosa romântica.

Essa estrutura se coaduna ao conceito aristotélico de narrativa e se alia à primazia do amor como indutor e condição necessária à felicidade nos produtos da cultura de massa e, especialmente, no cinema. Para Bordwell, sua prevalência se deu especialmente no chamado cinema clássico (entre as décadas de 1920 e 1950), mas é possível identificá-la na Hollywood contemporânea (pós-clássica ou neo-clássica, dependendo da corrente teórica). A permanência da estrutura causal dupla que privilegia o amor e, por conseqüência, o happy end do herói simpático no cinema de Hollywood comprova sua força. Isso porque se mantém atual a despeito do cinema de arte (o american art cinema); da ruptura com o modelo clássico nas décadas de 1960 e 1970; das vanguardas européias que influenciaram o cinema norteamericano.

\section{Elizabeth Bennet, heroína}

A segunda de cinco filhas do casal Bennet, Elizabeth Bennet vive numa ampla casa com a família, Longbourn. Todos temem o dia da morte do Sr. Bennet, pois a propriedade passará para o primo Collins, um desconhecido. Por conta da aflição, a sra. Bennet deseja, desesperadamente, casar as filhas para dar-lhes um futuro. Um belo dia, chegam ao campo o cavalheiro Mr. Bingley, sua irmã e o amigo deles, Mr. Darcy. Uma festa é dada para recebêlos. Bingley se apaixona por Jane, a Bennet mais velha (e unanimemente considerada a mais bonita da família). O sentimento é correspondido. Elizabeth, menos bonita e bastante atrevida, antipatiza ante o que julga ser uma frieza elitista de Darcy. A ligação entre Jane e Bingley é cortada graças à intervenção de Darcy, que despreza a família pouco elegante e, para ele, caça-níqueis, da moça. Ao mesmo tempo, se descobre apaixonado por Elizabeth, mas é rejeitado por ela. Por sua vez, Lizzie havia sido enganada pelas mentiras de Wickham, um 
aventureiro sedutor que "desencaminhou" a irmã mais nova de Darcy e já sabia da intervenção dele na infelicidade da irmã. Ao fim, descobre-se que Jane amava Bingley, mas era muito tímida para demonstrar, e Wickham é desmascarado - não sem antes levar uma das irmãs Bennet à ruína. Ajudada secretamente por Darcy, a família é salva da difamação. Diante da verdade, Elizabeth se rende ao amor por Darcy e as duas irmãs se casam com os amados.

Na versão de Orgulho e Preconceito dirigida por Joe Wright, de 2005, na qual focaremos neste artigo, a história de Elizabeth é contada mantendo a contextualização histórica original do romance. Lizzie é uma personagem bem delineada, com motivações evidentes. Personagem criada para a literatura (publicada originalmente em 1813), ela se encaixa ao modelo proposto por Bordwell do que seja o personagem do cinema clássico de Hollywood.

\footnotetext{
O filme hollywoodiano clássico apresenta indivíduos definidos, empenhados em resolver um problema evidente ou atingir objetivos específicos. Nessa sua busca, [...] entram em conflito com outros personagens ou com circunstâncias externas. [...] um indivíduo distinto dotado de um conjunto evidente e consistente de traços, qualidades e comportamentos (BORDWELL, 2005, p. 279).
}

Como personagem de narrativa audiovisual, é amada, também, porque suas angústias geram empatia no espectador, tornando-a um exemplar da heroína simpática de Morin. Heroína simpática com duas estruturas causais: uma interna, outra externa. De um lado, o amor romântico, a intriga que a deixa dividida/a decidir entre Wickham e Darcy. De outro, a casa como ameaça do desterro.

No que diz respeito à primeira linha, Lizzie tem de aprender a se despir de seus preconceitos, aprender a aceitar o amor. Não à toa, no terço final do filme, Lizzie diz ao pai: "Eu estava errada, profundamente errada". Pouco auto-consciente, o que ela deseja (Wickham) não é o que ela precisa (Darcy). Sua trajetória amorosa, portanto, é a de iluminarse e, assim, aprender a distinção entre a efemeridade apaixonada do desejo e a durabilidade do amor adequado e domesticado. Isso a torna mais consonante ainda com o cinema de Hollywood, segundo Maria Rita Kehl (1986). Para a autora, esse cinema tem uma dimensão inescapavelmente pedagógica e voltada para o amor romântico. Douglas Kellner também aponta esta dimensão pedagógica do que define como cultura da mídia: "são uma fonte profunda e muitas vezes não percebidas de pedagogia cultural: contribuem para nos ensinar como nos comportar e o que pensar e sentir, em que acreditar, o que temer e desejar - e o que não" (KELLNER, 2001, p. 10). 
A ideia de iluminação da personagem em busca da auto-consciência também se coaduna com o que diz Ashley Tauchert, para quem Austen trata, de alguma maneira, do potencial transformador da experiência. A mulher é o centro da narrativa, agente de cura e transformação. E tais mulheres, as protagonistas, são peças-chave para solucionar as contradições individuais e coletivas apresentadas pelas narrativas que protagonizam. Para serem agentes, essas mulheres passam por um processo de "reconhecimento" ou iluminação intelectual. É uma tendência ao empirismo, cuja experiência de iluminação da mente tem como resultado uma experiência de amor. Essa experiência leva ao desejo da personagem pelo final feliz, pelo casamento harmonioso. Este é alcançado por ações heróicas ou virtudes consideradas tipicamente femininas, acrescenta Tauchert, para quem "a narrativa do romance representa a busca do sujeito feminino para identificar e assegurar o amor "verdadeiro"" $\left(\right.$ TAUCHERT, 2005, p. 17) ${ }^{12}$.

A racionalidade defendida por Tauchert é reforçada no posfácio do crítico inglês Henry Hitchings a uma edição de Orgulho e Preconceito. De acordo com ele, "o romance ridiculariza a noção de amor à primeira vista, e Austen mostra que relações satisfatórias só podem se desenvolver gradualmente" (HITCHINGS, 2003, p. 486), ou seja, embaladas pela reflexão dos sujeitos amorosos a respeito do sentimento.

\section{Da casa à casa}

Além dessa trajetória de iluminação interna rumo a uma construção amorosa racional (ou, conforme consideramos mais apropriado, não apaixonada), Elizabeth também passa por outra trajetória, como McClane e os outros heróis do cinema. Há uma situação inicial, a saber a vaga possibilidade de perda futura da casa; esse status é abalado com a chegada de Collins, o futuro herdeiro, e com a possibilidade de que nenhuma das cinco filhas consiga fazer um bom casamento e, portanto, prover pelas outras. O reequilíbrio chega com o casamento de Lizzie com Darcy e a mudança dela para outra casa, Pemberley.

Mas ao contrário do herói masculino, que parte para o mundo em busca de uma aventura, Lizzie sai de sua casa para outra casa - a do marido. Não é uma versão feminina de Odisseu ou mesmo McClane. Quando Lizzie viaja, está bem acompanhada. A narrativa de Orgulho e Preconceito, assim, reafirma os perigos de a mulher empreender uma jornada externa. Lydia, a irmã mais nova que viaja a Bath com pessoas pouco conhecidas e pouco confiáveis, foge com Wickham e quase desgraça a família inteira com má reputação.

\footnotetext{
${ }^{12}$ Tradução livre da autora.
} 
Enquanto o herói pode desbravar mares, combater vilões, cavalgar entre regiões inglesas, a heroína tem de ser acompanhada, para evitar o descaminho. De um lado, a proteção à reputação da mulher. De outro, a desconfiança na capacidade de auto-governo feminina ${ }^{13}$.

No filme, o espaço de Lizzie se restringe às cercanias da casa, às casas da família, de Bingley, dos amigos. Esse é o território permitido à mulher. Se a personagem de Virginia Woolf em Um Teto Todo Seu fica trancada do lado de fora (da biblioteca), nossa heroína está trancada do lado de dentro. A mulher, assim, não empreende a trajetória do herói da cultura de massa que parte para o mundo e depois volta à casa - o mundo da protagonista é restrito, pequeno, circunscrito. É o que lhe é permitido percorrer.

A delimitação do espaço permitido a Lizzie é um dos elementos em que o audiovisual realiza uma iluminação ou tradução mais apuradas da obra da inglesa, interpretando o que a autora apenas sugeriu. A linguagem fílmica transforma os espaços abertos em permissões de liberdade. Na primeira sequência do filme, a protagonista lê enquanto caminha até em casa. A câmera oscila entre primeiros planos e planos abertos; a iluminação exala luminosidade do sol, da manhã (Figura 1); o som transborda de ruídos campestres. E então Lizzie entra em casa e o quadro se aproxima; confina a protagonista por meio de primeiros planos, close-ups e planos-detalhe. A iluminação, interna, aliada à mise-enscène de uma casa azulada, é mais baixa (Figura 2). O som que embala os movimentos da protagonista em casa não são os do campo. Ao contrário, a balbúrdia das irmãs, da mãe, das panelas. Nos tornamos cúmplices do mundo confinado de Lizzie, da falta de espaço. Falta tanto a ela, a casa a apreende e prende de tal maneira, que até no sono ela divide a cama com a irmã.

\footnotetext{
${ }^{13}$ Lizzie, ainda assim, é ousada. Quando a irmã mais velha, Jane, fica doente na casa de Bingley, ela caminha solitária pelo campo para socorrê-la.
} 


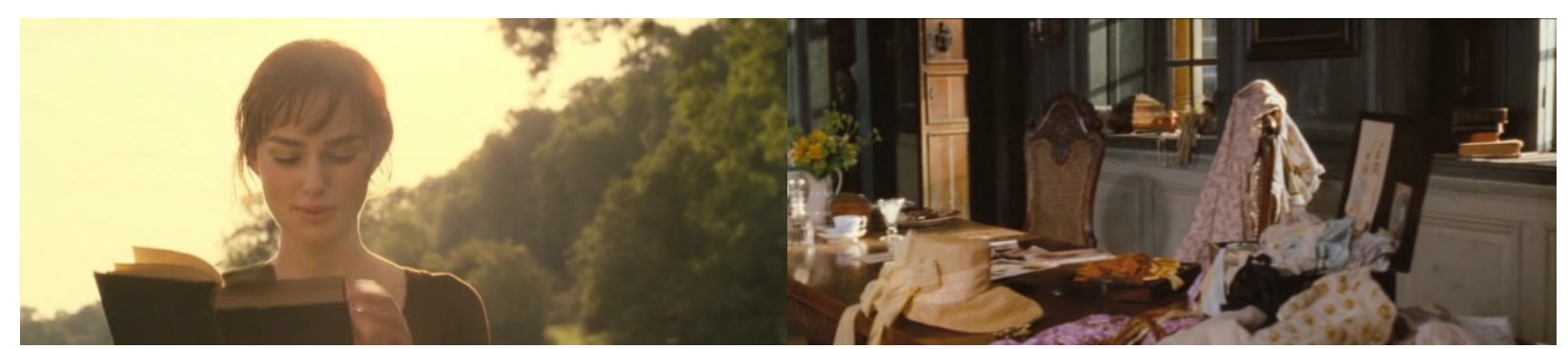

Figura 1: Primeiro plano iluminado enquanto Elizabeth Figura 2: bagunça e luz branda dentro de casa está fora de casa

Quando pode sair de casa (na sequência em que vai a Netherfield socorrer Jane, a irmã que ficou doente), a câmera se afasta em grande plano aberto e fixo. A protagonista é um detalhe no amplo cenário aberto, na liberdade do espaço sem cercas, sem paredes, sem confinamento (Figura 3). Ela percorre o quadro de um canto a outro. Logo, porém, chega à casa. E quando ela bate à porta, a câmera já se aproximou novamente, prenunciando a prisão que se achegará a ela. Os momentos em que Elizabeth pode caminhar pelo campo, como quando lê a carta de Darcy no bosque ou quando corre da igreja na chuva, são fugazes. São pontuações que anunciam o futuro da personagem: ser a esposa de Darcy.

Outras pontuações desta prisão são as passagens de tempo que demonstram a confusão mental da protagonista diante da confusão amorosa que, sem saber, já sente. Em uma sequência, a personagem está sentada num balanço do quintal de casa. Ela gira, gira, e passam as estações (Figura 4). A câmera alterna entre planos americanos fixos da protagonista e o que os olhos dela vêem, em dollys de 360 graus: o sol, a chuva, a neve. O mesmo cenário - a casa, o quintal, as paredes. A elipse implica que, durante todo aquele tempo, aquele foi o espaço ocupado por ela, percorrido não apenas pelo olhar. Enquanto isso, constrói-se sua trajetória de auto-conhecimento confinado. Sem poder ir ao mundo, ela pode apenas aprender remoendo sentimentos, acordada à noite enquanto a irmã dorme ao lado. Não há terroristas a matar com um revólver; há o processo solitário e silencioso de iluminação e racionalização.

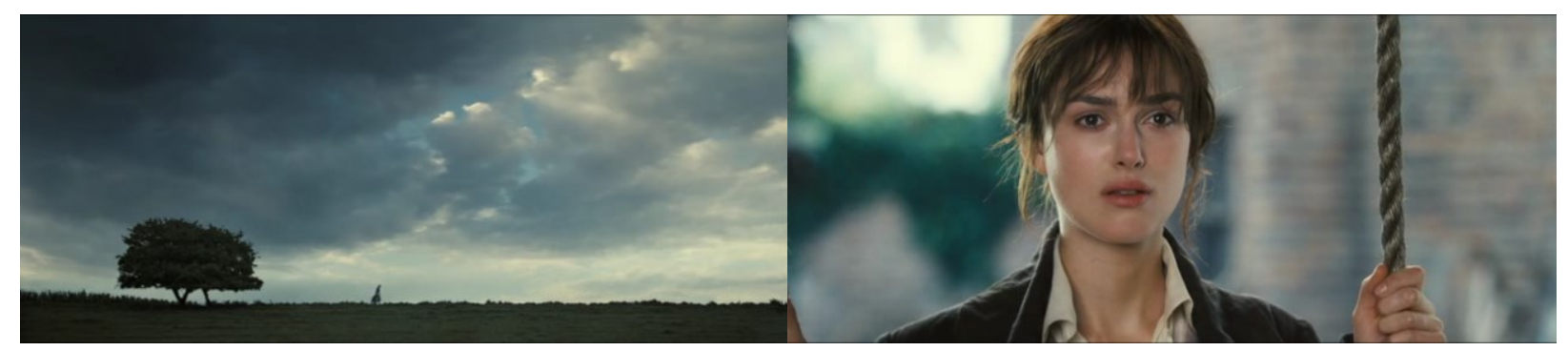


Figura 4: movimento da câmera faz elipse temporal e indica que a personagem não saiu daquele espaço

Por enquanto, Lizzie ainda está em casa, aquele espaço que a aprisiona em uma família de excessos de comportamento plebeu; de falta de recursos. De barulhos e vergonhas públicas. Ao longo do filme, ela faz duas viagens. Uma delas, sozinha, em direção à segurança da casa da amiga Charlotte. A outra, com os tios, a leva para a casa que é o destino final de sua narrativa: Pemberley, a casa de seu futuro marido. Sua futura casa. A entrada dela na propriedade casa ilustra bem o movimento da linguagem que marca a postura da narrativa com relação aos espaços permitidos a ela.

Lizzie viaja com os tios pelo interior. Vertical, a câmera a focaliza em noventa graus, de cima para baixo, deitada na carroça. Olhos fechados, os raios do sol entram pelas pálpebras. Ela sorri. Quando entra em Pemberley, novamente a câmera a focaliza de cima para baixo (mais radical que o plongée), mas agora a diminui perante a grandiosidade do espaço. Maravilhada, caminha pelo piso de mármore preto e branco. Ri, agora encabulada.

A primeira visão de Pemberley também é marcante. O filme nos mostra um grande plano onde, por entre folhas, começamos a desvendar uma enorme casa no segundo plano. Corta para Lizzie, que, surpresa, vê o local pela primeira vez. Seus olhos brilham. Ela ri de incredulidade. À medida que Lizzie investiga a casa, a câmera se aproxima, tornando a personagem mais íntima do espaço e também a confinando. Suas mãos tocam detalhes, o plano se torna americano.

\section{Casas com nome}

As casas, em Orgulho e Preconceito, são quase personagens sem falas, mas com personalidade - e nomes. A sequência de abertura do filme apresenta o campo, em câmera fixa, que se move para encontrarmos Lizzie lendo, enquanto caminha. Passa por varais, pela ponte rodeada de animais, pela porta. Deixamos de segui-la e a câmera entra na casa dos Bennet, desvendando em plano americano desordem, irmãs, luz. A câmera sai por outra porta e voltamos à Lizzie, enquanto ela vai entrar em casa. Longbourn, um personagem, tem personalidade: desorganizada, mal iluminada, barulhenta. À maneira da apresentação de um personagem no audiovisual, é descrita pela câmera em movimento, que a revela cenicamente. Ao final da introdução do filme, a casa da família é focalizada sozinha, enquanto a câmera se afasta até um plano geral, em tableau. O cenário imóvel do status quo que Elizabeth irá romper em busca de um novo, Pemberley. 
Orgulho e Preconceito se infiltra por dentro das casas pelas quais Elizabeth passa. Quando ela vai ao baile em Netherfield, a câmera passeia por ambientes, detalhes, pessoas, rostos. Ao final do baile, a câmera é um olho que perscruta o cenário atrás da heroína, a quem segue incessantemente. A encontra em plano americano, num canto escuro, encostada à parede, apoiada nos alicerces da casa, sozinha. Netherfield, uma casa opulenta e rica.

A personalidade de Pemberley, a futura casa daquela que será Mrs. Darcy, se apresenta logo como um espaço além da opulência. É uma casa elegante. O conceito fica claro logo na tomada do piso em preto-e-branco, mas também na sala das esculturas, onde o branco predominante do mármore revela a família tradicional, de gerações de cavalheiros, heróis de guerra, nobres. Quando Lizzie entra nos aposentos mais íntimos e seus dedos percorrem os objetos da casa em planos-detalhe, a personalidade ensolarada de Pemberley fica ainda mais clara - o cenário é uma grande mansão envidraçada. Por uma das enormes janelas, vê-se um jardim bem-cuidado e amplo.

Como território permitido à mulher, a casa, espaço da intimidade, mas também da domesticidade e da imanência, é onde ela tem permanecido por milhares de anos (WOOLF, 1985). A mulher de Woolf, em Um teto todo seu, de fato só tem a casa para circular: é expulsa do gramado; tenta ir à biblioteca - onde são admitidas apenas mulheres acompanhadas. “(...) Eu era uma mulher (...) meu lugar é no cascalho" (WOOLF, 1985, p. 10). Como único território feminino, não é de estranhar que a casa seja tratada de maneira tão personalizada no filme - que ganhe direção e mise-en-scène bastante elaboradas, em contraste com a construção usualmente reificada da casa apenas como cenário, pano de fundo, para a ação dramática, que o cinema hollywoodiano apresenta em geral.

\section{A virgem que fica, a perdida que parte}

O filme se ancora em alguma das construções dicotômicas da imagem feminina que o cinema explora, conforme Ann Kaplan. A irmã mais nova, Lydia, representa a sexualidade e a perdição. A mulher que viaja sozinha, a (anti)heroína que ousa desgarrar-se. Não poderia haver outra solução para Lydia senão um casamento que tente abafar o descaminho sexual. Lizzie, a que fica (assim como Jane, que também fica - e é ainda mais imanente que a irmã), é premiada com um casamento no qual pode se dar ao luxo de amar; um casamento com um homem rico. Ela é a virgem.

Essas imagens dicotômicas, esses duplos opostos, são, segundo Rosana Kamita, "utilizadas à exaustão, especialmente pelo cinema narrativo clássico, cujo paradigma é aquele 
realizado por Hollywood." (KAMITA, 2006, p. 2). São as clássicas divisões "entre mulheres virtuosas e não-virtuosas" (KAMITA, 2006, p.2), vamps sedutoras versus mães virtuosas. Maria Helena Braga e Vaz da Costa lembra que Ann Kaplan identifica

\begin{abstract}
três tipos de mulher produzidos por Hollywood desde os anos 1930 até a atualidade: (1) a mulher 'cúmplice', que renuncia aos seus sentimentos pessoais e à sua realização individual, assumindo uma postura frágil; (2) a mulher 'resistente', que surge no século XX com sua integração ao mercado de trabalho e sua emancipação financeira, graças ao movimento feminista; (3) a mulher 'pós-moderna', que, tendo encontrado espaço na esfera econômica e política, conquista a liberdade de escolha desejada e enfrenta as novas e complexas questões que se originam na contemporaneidade. (COSTA, 2009, p. 107)
\end{abstract}

Que mulher é Lizzie? Ora, nossa heroína é cinematográfica, mas imaginada pelas páginas pré-vitorianas de Austen em 1799. Não é uma mulher pós-moderna, nem uma mulher do século XX. É uma personagem que não renuncia aos sentimentos, mas ao contrário, os reafirma e exerce o direito de vivenciá-los a despeito da família (é, portanto, uma personagem com motivações egoístas). Mas a coroação de sua trajetória nada mais é, por outro lado, que a coroação da mulher como esposa, da mulher como "Mrs.”. Antes livre para caminhar pelo prado, depois de casada, Lizzie tem a ampla propriedade de Pemberley para seu desfrute. Mas está circunscrita aos limites da terra do marido.

$\mathrm{Na}$ versão norte-americana do filme (diferente da versão que foi distribuída internacionalmente), há um epílogo. O filme se encerra com o pai de Lizzie concedendo a mão da filha ao cavalheiro. Nos EUA, os espectadores viram outra cena ainda (disponível na versão em DVD e Blu-ray). Um pátio de Pemberley, noite, luz de velas, taças de vinho. Plano médio do casal. Darcy e Lizzie estão sentados e ele pergunta como ela quer que a chame. Ela responde beijando as mãos dele, rosto, cabelo, boca. "Depende do momento", ela diz. Nos mais felizes, quer ser chamada de "Mrs. Darcy". Se o herói masculino encontra na casa abrigo seguro depois de enfrentar o mundo, Lizzie só tem a opção de encontrar na casa do futuro marido abrigo a uma outra casa, em que ela é estranha diante da desordem, da inadequação social, da balbúrdia.

\title{
Uma casa ideal
}

Sair de uma casa ameaçada pela perda e adentrar na casa do marido, na segurança de Pemberley, é motivo de felicidade para a heroína de Orgulho e Preconceito. A trajetória que a leva de uma casa a outra (de um equilíbrio inicial a outro status quo) sem, no entanto, ir para lugar algum entre estes dois pontos apresenta este personagem casa como um espaço seguro 
de afeto na esfera privada. Como o lócus onde o indivíduo encontra acolhida ao mundo. Mas esse não é, historicamente, um espaço tão conciliador assim.

A casa é representada como espaço consagrado da família nuclear pré-moderna de que Lizzie se torna a esposa e, futuramente, mãe. Nancy Fraser diz que essa família é uma das instituições especializadas na reprodução simbólica, e que diz respeito àquilo que Habermas se referia como "esfera privada", ou como Fraser interpreta, "as ordens institucionais do moderno mundo da vida, os domínios integrados socialmente, especializados em reprodução simbólica, isto é, na socialização, formação da solidariedade e transmissão cultural" (FRASER, 1987, p. 44), em uma estrutura institucional que ela classifica como dualista, pois tem de um lado a família nuclear e a esfera pública e, de outro, a economia capitalista e o Estado.

Apresentar a casa como tal espaço conciliador e abrigo afetivo esconde, e o filme o faz, a outra dimensão da esfera privada de Lizzie como esposa: sua subordinação ao marido (FRASER, 1987, p. 45) e o fato de que seu espaço como esposa só permite ocupações nomeadamente femininas. A mãe de Lizzie, mulher de família mais pobre, ainda é vista gerenciando a casa, escolhendo a carne do jantar e organizando as atividades serviçais aquelas atuações invisíveis que são o liame da harmonia doméstica que o marido experiencia quando recebe o hóspede para jantar. Mas Elizabeth, agora a esposa de um cavalheiro, de um nobre, não é mostrada nem perto das atividades servis - mas, se não é a ela que cabe diretamente a feitura dessas atividades domésticas, a ela cabe, como mulher, a administração de todas elas.

A família, simbolizada pela nova casa da qual ela é senhora (governanta?), não é apenas o lócus do exercício do afeto, mas, de acordo com Fraser,

lugares de cálculo egocêntrico, estratégico e instrumental bem como lugares de trocas usualmente exploradoras, e de serviços, trabalho, dinheiro, sexo e, inclusive, às vezes, frequentemente coerção e violência (...) lugares de trabalho, troca, cálculo, distribuição e exploração (FRASER, 1987, p. 45).

Ou seja, a casa não é abrigo num mundo impiedoso, mas cálculo instrumental e estratégico.

\section{Considerações finais}

A casa onde Lizzie irá morar, a casa onde ela já vive no epílogo norte-americano do filme, só é apresentada pelo audiovisual como portadora de uma possibilidade desse espaço 
de convivência familiar: do amor e da afeição. É onde Elizabeth será beijada pelo marido; onde ela será amiga, "irmã” de Georgina Darcy, a irmã mais nova do marido, que quando a conhece a recebe com um caloroso abraço. É uma visão idílica, irreal, que o cinema amplifica com a câmera reverente e intrusiva com que focaliza todas as casas do filme. É como se a linguagem fílmica nos dissesse, como disse Dorothy: "Não há lugar melhor que nosso lar".

Um lugar ficcional muito diferente do lugar real histórico que as mulheres habitaram por séculos. Um lugar ficcionalizado de um passado distante, a virada do século XVIII para o século XIX. Mas que é explorado pelo cinema hollywoodiano contemporâneo, o que nos faz indagar: por quê? Não apenas pela qualidade narrativa de Austen nem pela adequação da trama e personagens ao modelo clássico. Mas, acreditamos, também pela propagação institucional de uma visão de amor e afeto ligada à trajetória interna da heroína. Essa visão apresenta o confinamento ao espaço interior como algo desejável e bom, como algo a conquistar - quando, na verdade, pode ser apenas uma constante lembrança da submissão da mulher a papeis dominados, da heroína que tem de conquistar-se (já que não pode conquistar o mundo); da esposa que é senhora do lar - mas apenas da casa.

Ao investir nas adaptações constantes de obras de Austen, o audiovisual escamoteia outras possibilidades de trajetória contemporâneas que a heroína tem, investe na consagração do amor romântico e no incentivo para que a mulher fique contida ao espaço do privado. Ainda que haja lugares melhores que o lar, um certo cinema de Hollywood, aquele que fala de amor, prefere que a mulher não descubra isso.

\section{Referências}

AUSTEN, Jane. Pride and Prejudice. Londres: CRW Publishing Limited, 1815; 2003.

BORDWELL, David. O cinema clássico hollywoodiano: normas e princípios narrativos. In RAMOS, Fernão Pessoa (org.) Teoria Contemporânea do Cinema - Documentário e Narratividade Ficcional volume 2. São Paulo: Senac, 2005, p. 277-302.

CARROLL, Laura. A consideration of times and seasons: two Jane Austen adaptations. In: Literature/Film Quarterly, v. 31, 2003.

COSTA, Maria Helena Braga e Vaz. Mulheres partidas: poética e política das imagens fílmicas da mulher. Bagoas - Estudos gays, gêneros e sexualidades: revista do Centro de Ciências Humanas, Letras e Artes da Universidade Federal do Rio Grande do Norte, Natal, vol. 2, $\quad \mathrm{n}^{\mathrm{o}} \quad 3, \quad$ p.97-114, 2009. Disponível em: $<$ http://www.cchla.ufrn.br/bagoas/v02n03art05_costa.pdf $>$. Acesso em: 21 fev. 2012. 
FERGUSS, Jan. The professional woman writer. In: COPELAND, Edward e MCMASTER, Juliet (orgs.). The Cambridge Companion to Jane Austen. $11^{\mathrm{a}}$ impressão. Cambridge: Cambridge University Press, 2008.

FRASER, Nancy. O que é crítico na teoria crítica? O argumento de Habermas e o gênero. In: BENHABIB, Seyla e CORNELL, Drucilla. Feminismo como crítica da modernidade. Trad. Nathaniel da Costa Caixeiro. Rio de Janeiro: Record, 1987.

HITCHINGS, Henry. Afterword. In: AUSTEN, Jane. Pride and Prejudice. Londres: CRW Publishing Limited, 2003. pp. 483-490.

KAMITA, Rosana Cássia. Luz e sombra: relações de gênero no cinema. In FAZENDO GÊNERO, 7. UFSC, Florianópolis, 2006. Ruídos na representação da mulher: preconceitos e estereótipos na literatura e em outros discursos. Disponível em: $<$ http://www.fazendogenero.ufsc.br/7/artigos/R/Rosana_Kamita 13 B.pdf> $>$, acesso em: $20 \mathrm{de}$ fevereiro de 2012.

KEHL, Maria Rita. Cinema e Imaginário. In: XAVIER, Ismail (org). O cinema no século. Rio de Janeiro: Imago, 1986. pp. 107-121.

KELLNER, Douglas. A Cultura da Mídia. Trad. Ivone Castilho Benedetti. Bauru, SP: Edusc, 2001.

MORIN, Edgar. Cultura de Massas no Século XX: O Espírito do Tempo, volume $1.10^{\mathrm{a}} \mathrm{Ed}$. Rio de Janeiro: Forense Universitária, 2011.

TAUCHERT, Ashley. Romancing Jane Austen: narrative, realism and possibility of a happy ending. Houndmills, Basingtoke, Hampshire e Nova York: Palgrave Macmillan, 2005.

TODOROV, Tzvetan. As estruturas narrativas. Trad.: Leyla Perrone-Moisés. São Paulo: Perspectivas, 2006.

WOOLF, Virginia. Um teto todo seu. Trad. Vera Ribeiro. Rio de Janeiro: Nova Fronteira, 1985.

Créditos das imagens: Reprodução.

[Recebido em março de 2012 e aceito para publicação em dezembro de 2012]

There is no place like home - the house as confinement, character and idealized space in the movie Pride and Prejudice

Abstract: This paper analyzes three ways in which the figure of the house is represented in the 2005's film version of the book Pride and Prejudice: as a space of confinement, as a character and as idealized space of affection. To serve as a support for the analysis of this adaptation of one of Jane Austen's books, we use the theories of film and mass culture and feminist theories. To look on the cinematic language of the audiovisual work allows us to show how, far from being an idealized and pacified space as the film tries to present, the figure of the house is usurped of all other meanings in the narrative and especially in the story 
of the female characters, to offer a fictional strengthening of the patriarchal view of the house as the only space allowed to heroin, which is allowed to move in very different spaces from those covered by the male hero.

Keywords: Cinema. House. Love. Adaptation. Happy end

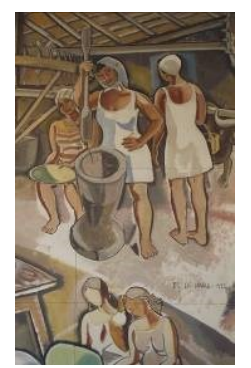

